\title{
Variation in trait trade-offs allows differentiation among predefined plant functional types: implications for predictive ecology
}

\author{
Lieneke M. Verheijen ${ }^{1}$, Rien Aerts ${ }^{1}$, Gerhard Bönisch ${ }^{2}$, Jens Kattge ${ }^{2}$ and Peter M. Van Bodegom ${ }^{1,3}$ \\ ${ }^{1}$ Systems Ecology, Department of Ecological Science, VU University Amsterdam, De Boelelaan 1085, 1081 HV, Amsterdam, the Netherlands; ${ }^{2}$ Max Planck Institute for Biogeochemistry, Hans \\ Knoell Strasse 10, 07745, Jena, Germany; ${ }^{3}$ Institute of Environmental Sciences, Leiden University, Einsteinweg 2, 2333 CC, Leiden, the Netherlands
}

Authors for correspondence:

Lieneke M. Verheijen

Tel: +31205986989

Email: I.m.verheijen@vu.nl

Peter M. Van Bodegom

Tel: +31715277486

Email: p.m.van.bodegom@cml.leidenuniv.nl

Received: 22 April 2015

Accepted: 28 July 2015

New Phytologist (2016) 209: 563-575

doi: $10.1111 /$ nph.13623

Key words: kernel density estimation, plant functional types, plant strategies, plant traits, trade-offs, trait variation.

\section{Summary}

- Plant functional types (PFTs) aggregate the variety of plant species into a small number of functionally different classes. We examined to what extent plant traits, which reflect species' functional adaptations, can capture functional differences between predefined PFTs and which traits optimally describe these differences.

- We applied Gaussian kernel density estimation to determine probability density functions for individual PFTs in an $n$-dimensional trait space and compared predicted PFTs with observed PFTs. All possible combinations of 1-6 traits from a database with 18 different traits (total of 18287 species) were tested.

- A variety of trait sets had approximately similar performance, and 4-5 traits were sufficient to classify up to $85 \%$ of the species into PFTs correctly, whereas this was $80 \%$ for a bioclimatically defined tree PFT classification. Well-performing trait sets included combinations of correlated traits that are considered functionally redundant within a single plant strategy.

- This analysis quantitatively demonstrates how structural differences between PFTs are reflected in functional differences described by particular traits. Differentiation between PFTs is possible despite large overlap in plant strategies and traits, showing that PFTs are differently positioned in multidimensional trait space. This study therefore provides the foundation for important applications for predictive ecology.

\section{Introduction}

Plant functional type (PFT) classifications are used to aggregate the enormous number of plant species into a relatively small number of functionally different classes. As the term implies, a PFT classification should be functional, based on ecological concepts, and differentiate between groups of plants with similar responses to changes in their environment and with comparable impacts on this environment (Diaz \& Cabido, 1997; Lavorel \& Garnier, 2002). Classifications of plants have a long history (for an overview of the development of the PFT concept, see Ustin \& Gamon, 2010; Wullschleger et al., 2014) and are broadly applied in ecology as well by the modeling community. Especially when making predictions at regional to global scales, there is a need to aggregate species into a simplified, workable number of functional groups, thereby reducing the need for knowledge on the underlying species.

Although there are different conceptualizations of PFTs, for example based on structural aspects (growth forms), environmental constraints or plant traits (Box, 1996; Lavorel et al., 1997, 2007; Woodward \& Kelly, 1997; Harrison et al., 2010), (global) applications of PFTs are often classified 'a priori based on growth form. The idea behind such classification is that growth forms reflect structural adaptations to different environmental conditions, that is 'form follows function' (Box, 1996). In addition to basic growth forms, depending on the application, characteristics related to, for example leaf phenology (deciduous vs evergreen), leaf structure (broadleaved vs needleleaved) or photosynthetic pathway add subdivisions within growth forms. Growth forms and their derived PFTs are a basic first division reflecting and explaining differences in plant functioning in relation to environmental conditions (Lavorel etal., 1997; Reich etal., 2007; Kattge et al., 2011). Such a classification is commonly used in applications such as global vegetation mapping and investigations on the impacts of climate change, land use change or management strategies on vegetation cover.

A way to quantitatively test how functional differences between PFTs are related to (structural) plant properties is to investigate their positioning in multidimensional domains of plant functional traits. Plant traits are a suitable tool for describing different functional aspects of plants and their relations to environmental conditions, because the different growth and survival strategies of plants in response to (a)biotic determinants such as water, light and nutrient availability, competition and 
disturbances are reflected by a plant's set of trait values (Westoby et al., 2002; Reich et al., 2003; Reich, 2014). As a consequence of the different strategies of plants, trait values vary between species (both within and between habitats). By relating this variation in traits to a number of largely independent strategy axes (or 'axes of trait variation'; Westoby, 1998), differences in plant strategies between species can be explained. For example, the leaf-heightseed strategy scheme (Westoby, 1998) distinguishes three functionally different strategy axes, which relate variation in leaf traits, like specific leaf area (SLA) and leaf life span (LLS) (so called 'leaf economics' traits), to differences in growth and resource acquisition (Reich et al., 1999; Wright et al., 2004; Reich, 2014), variation in seed mass (SM) and output to variation in reproductive strategies (Moles \& Westoby, 2004; Moles et al., 2004) and variation in plant height to differences in strategies concerning light competition and disturbances (Westoby, 1998; Westoby et al., 2002).

Different methods that use traits to distinguish among vegetation types or to describe functional classifications have been developed (Diaz \& Cabido, 1997; Pillar \& Sosinski, 2003). Combinations of traits with different functional roles may be particularly useful for differentiating between different plant strategies and consequently allow classification of functionally different groups of plant species (Diaz etal., 2004; Boulangeat etal., 2012). However, the extent to which predefined growth formbased PFTs can be described from a bottom-up, functional traitsbased approach has not been quantified yet. Global scale analyses can clarify which traits are most important in explaining functional differences between growth forms and, as such, reveal which functional aspects of plants underlie differences in growth forms. In addition, knowing both the extent to which plant traits can quantitatively discriminate between PFTs as well as knowing the most important traits is highly relevant, as it would allow global vegetation mapping based on trait maps. Such global trait maps can be constructed relatively easily based on the relationships between traits and climate (Van Bodegom etal., 2014). Even though there is large overlap in traits between growth forms or PFTs (Reich et al., 2003, 2007; Wright et al., 2005; Kattge et al., 2011; Van Bodegom et al., 2012; Verheijen et al., 2013), suggesting substantial overlap between functional strategies of PFTs, combinations of (functional different) traits might allow discrimination between PFTs. With this information, changes in vegetation distribution upon climate change can be predicted based on modifications in plant trait values.

We investigated to what extent plant traits can capture functional differences between growth forms and their derived PFTs by analyzing how well these PFTs can be differentiated from each other based on plant traits, and which (sets of) traits are needed to describe these functional differences between PFTs. We did not define a priori the most important traits, but tested a whole range of traits from different plant strategy dimensions, including various 'core' traits, related to dispersal, establishment and persistence of plants (Weiher et al., 1999; Cornelissen et al., 2003b). We asked whether combinations of traits that reflect different functional aspects within plants (e.g. competition for water, light, drought tolerance) will capture functional differences between
PFTs best and consequently will have the highest potential to differentiate among PFTs.

\section{Materials and Methods}

\section{Data collection and selection}

We collected plant trait data related to different functional roles in plants. The main source was the TRY database (Kattge et al., 2011) (accession date 16 November 2010), which included data from both unpublished studies (H. Kurokawa, unpublished; W. J. Bond, unpublished; F. S. Chapin III, unpublished; A. Siefert, unpublished; E. E. Sosinski, unpublished; E. Weiher, unpublished) and published studies (Leishman \& Westoby, 1992; Shipley, 1995; Cornelissen, 1996; Cornelissen et al., 1996, 1997; Bahn et al., 1999; Medlyn \& Jarvis, 1999; Medlyn et al., 1999; Meziane \& Shipley, 1999; Niinemets, 1999; Pyankov et al., 1999; Wohlfahrt et al., 1999; Fonseca et al., 2000; White et al., 2000; Craine et al., 2001; Medlyn et al., 2001; Niinemets, 2001; Klotz et al., 2002; Shipley \& Vu, 2002; Cornelissen et al., 2003a; Loveys et al., 2003; Ogaya \& Penuelas, 2003; Pillar \& Sosinski, 2003; Poschlod et al., 2003; Quested et al., 2003; Cornelissen etal., 2004; Diaz et al., 2004; Moles \& Westoby, 2004; Moles etal., 2004; Wright etal., 2004; Craine etal., 2005; Han etal., 2005; Kirkup etal., 2005; Louault etal., 2005; Moles etal., 2005; Soudzilovskaia et al., 2005; Bakker et al., 2006; CavenderBares et al., 2006; Cornwell et al., 2006; He et al., 2006; Kazakou etal., 2006; Ogaya \& Penuelas, 2006; Preston etal., 2006; Wright et al., 2006; Ackerly \& Cornwell, 2007; Blanco et al., 2007; Campbell etal., 2007; Duarte etal., 2007; Muller etal., 2007; Ogaya \& Penuelas, 2007; Swaine, 2007; Wright etal., 2007; He etal., 2008; Kleyer etal., 2008; Kurokawa \& Nakashizuka, 2008; Ogaya \& Penuelas, 2008; Pakeman etal., 2008; Paula \& Pausas, 2008; Reich et al., 2008; Sardans et al., 2008a,b; Van Bodegom et al., 2008; Baker et al., 2009; Chave etal., 2009; Craine etal., 2009; Fortunel et al., 2009; Fyllas et al., 2009; Kattge et al., 2009; Laughlin \& Moore, 2009; Pakeman et al., 2009; Paula et al., 2009; Poorter etal., 2009; Reich etal., 2009; Wirth \& Lichstein, 2009; Zanne et al., 2009; Freschet et al., 2010a,b; Laughlin et al., 2010; Messier etal., 2010; Ordoñez et al., 2010; Wright et al., 2011; Onipchenko et al., 2012; Soudzilovskaia et al., 2013). Additional data was collected from other publicly available and private databases (Hendricks et al., 2000; Pregitzer et al., 2002; Craine \& Lee, 2003; Comas \& Eissenstat, 2004, 2009; Tjoelker et al., 2005; Kerkhoff etal., 2006; Pittermann etal., 2006; Roumet etal., 2006; Green, 2009; Liu etal., 2010; Zanne etal., 2010; Holdaway et al., 2011; Choat et al., 2012; Douma et al., 2012b; McCormack et al., 2012; Fort et al., 2013; Tobner et al., 2013) or unpublished data (P. M. van Bodegom, unpublished). The traits are listed in Table 1. In light of the debate on area- vs massbased photosynthesis-related traits (Lloyd et al., 2013; Westoby et al., 2013), both mass- and area-based estimates of leaf traits were investigated for leaf nitrogen content $\left(\mathrm{LNC}_{\text {mass }}\right.$ and $\left.\mathrm{LNC}_{\text {area }}\right)$, maximum photosynthetic rate $\left(A_{\text {max,mass }}\right.$ and $\left.A_{\text {max,area }}\right)$ and leaf dark respiration $\left(\mathrm{Rd}_{\text {mass }}\right.$ and $\left.\mathrm{Rd}_{\text {area }}\right)$. To eliminate a small 
Table 1 List of traits used in the different plant functional type (PFT) classification analyses

Classification

\begin{tabular}{|c|c|c|c|c|c|}
\hline \multirow[b]{2}{*}{ Trait } & \multirow[b]{2}{*}{ Abbreviation } & \multirow[b]{2}{*}{ Unit } & \\
\hline & & & 7-PFT & $6-\mathrm{PFT}$ & Tree PFT \\
\hline Leaf life span & LLS & months & & $x$ & $x$ \\
\hline Specific leaf area & SLA & $\mathrm{mm}^{2} \mathrm{mg}^{-1}$ & $x$ & $x$ & $x$ \\
\hline Mass based maximum photosynthetic rate & $A_{\text {max,mass }}$ & $\mu \mathrm{mol} \mathrm{g} \mathrm{g}^{-1} \mathrm{~s}^{-1}$ & $x$ & $x$ & $x$ \\
\hline Area based maximum photosynthetic rate & $A_{\max , \text { area }}$ & $\mu \mathrm{mol} \mathrm{m}{ }^{-2} \mathrm{~s}^{-1}$ & $x$ & $x$ & $x$ \\
\hline Mass based leaf dark respiration & $\mathrm{Rd}_{\text {mass }}$ & $\mu \mathrm{mol} \mathrm{g} \mathrm{g}^{-1}$ & & $x$ & $x$ \\
\hline Area based leaf dark respiration & $\mathrm{Rd}_{\text {area }}$ & $\mu \mathrm{mol} \mathrm{m} \mathrm{m}^{-2} \mathrm{~s}^{-1}$ & & $x$ & $x$ \\
\hline Mass based leaf nitrogen content & $\mathrm{LNC}_{\text {mass }}$ & $\mathrm{mg} \mathrm{g}^{-1}$ & $x$ & $x$ & $x$ \\
\hline Area based leaf nitrogen content & $\mathrm{LNC}_{\text {area }}$ & $\mathrm{g} \mathrm{m}^{-2}$ & $x$ & $x$ & $x$ \\
\hline Leaf phosphorus content & $\mathrm{LPC}_{\text {mass }}$ & $\mathrm{mg} \mathrm{g}^{-1}$ & $x$ & $x$ & $x$ \\
\hline Leaf carbon content & $\mathrm{LCC}_{\text {mass }}$ & $\mathrm{mg} \mathrm{g}^{-1}$ & $x$ & $x$ & $x$ \\
\hline Leaf area & LA & $\mathrm{mm}^{2}$ & $x$ & $x$ & $x$ \\
\hline Stomatal conductance & $G_{s}$ & $\mathrm{~mol} \mathrm{~m}^{-2} \mathrm{~s}^{-1}$ & $x$ & $x$ & $x$ \\
\hline Leaf dry matter content & LDMC & $\mathrm{g} \mathrm{g}^{-1}$ & $x$ & $x$ & $x$ \\
\hline Maximum plant height & $\mathrm{MPH}$ & $\mathrm{m}$ & $\mathrm{x}$ & $\mathrm{x}$ & $x$ \\
\hline Seed mass & SM & $\mathrm{mg}$ & $x$ & $x$ & $x$ \\
\hline Stem specific density & SSD & $\mathrm{mg} \mathrm{m}^{-3}$ & & $x$ & $x$ \\
\hline Vessel area & VA & $\mathrm{mm}^{2}$ & & & $x$ \\
\hline Water potential at which $50 \%$ loss of conductivity occurs & $\Psi 50$ & $\mathrm{MPa}$ & & & $x$ \\
\hline Minimum rooting depth & MinRD & $\mathrm{m}$ & $x$ & $x$ & $x$ \\
\hline Root nitrogen content & $\mathrm{RNC}_{\text {mass }}$ & $\mathrm{mg} \mathrm{g}^{-1}$ & $x$ & $x$ & \\
\hline Specific root length & SRL & $\mathrm{cm} \mathrm{g}^{-1}$ & $x$ & $\mathrm{x}$ & \\
\hline
\end{tabular}

number of biologically impossible trait values while preventing selective removal of entries in PFTs occurring at the upper and lower boundaries of trait values, only data within the $99 \%$ quantiles of every PFT separately were selected. For most individuals of a species, only a subset of the traits was measured, which resulted in a database with many trait gaps. By calculating species means, the database became smaller, but the number of traits per species increased, allowing us to investigate more trait combinations. This database based on species means consisted of 18287 species for which information for one or more traits was available.

\section{PFT classification}

Species were assigned to a PFT based on the categorical data available from multiple trait data sources, the most important being the TRY database. These included plant growth form, leaf phenology, leaf type and photosynthetic pathway. When no information about $\mathrm{C}_{3}$ - or $\mathrm{C}_{4}$-photosynthesis was available, the species was assumed to be a $\mathrm{C}_{3}$-species. Species that could not be classified because of missing or ambiguous categorical data were omitted. Species known not to belong to the seed plants, species with crassulacean acid metabolism (CAM)-photosynthesis, succulent species (e.g. cacti), climbers or vines, (hemi-)parasitic species, aquatic species, (hemi)-epiphytes, crops and palmoids were left out as well, because little data trait was available for these plant types.

Different PFT classifications were evaluated. The first PFT classification consisted of seven broadly applied PFTs (including only angiosperms and gymnosperms): $\mathrm{C}_{3^{-}}$and $\mathrm{C}_{4}$-graminoids (including grasses, sedges and rushes), $\left(\mathrm{C}_{3^{-}}\right)$forbs, $\left(\mathrm{C}_{3^{-}}\right.$)shrubs, broadleaved deciduous trees, broadleaved evergreen trees and needleleaved evergreen trees. Needleleaved deciduous trees could not be included, because of trait data limitations (a minimum of seven species per trait (set) per PFT was needed, explained in the next section). For this classification, there were 15 traits with sufficient species per PFT to be included in the analyses (see Table 1). The number of species within the $\mathrm{C}_{4}$-graminoid PFT was too low to include a number of traits considered to be important in plant survival strategies (stem specific density, SSD, and LLS). Therefore, a six-PFT classification was constructed, with $\mathrm{C}_{4-}$ and $\mathrm{C}_{3}$-graminoids merged into a single graminoids PFT. This allowed additional inclusion of LLS, SSD and $\mathrm{Rd}_{\text {mass }}$ and $\mathrm{Rd}_{\text {area. }}$. The distribution and number of observations (species' means) per PFT and per trait are listed in Supporting Information Fig. S1.

We also tested a PFT classification of trees only, which included bioclimatic descriptions. This classification de-emphasizes the role of plant height as a descriptor of growth form and allowed the inclusion of a number of additional traits; vessel area (VA) and the water potential at which $50 \%$ loss of conductivity occurs ( $\Psi 50)$. To associate each species to a climate zone, species distributions were determined based on their spatial occurrences in the Global Biodiversity Information Facility (http:// www.gbif.org, data accessed 18 October 2014), extracted with the R-package RGBIF (Chamberlain et al., 2014). The climate zone within the Köppen-Geiger climate classification (Kottek et al., 2006) with most occurrences was taken to represent the correct climate zone that a species originated from. For species occurring mostly in deserts, the climate zone with the second most occurrences for this species was taken. The different climatic zones were aggregated into tropical (equatorial climates), extratropical (warm temperate climates, snow and polar climates, 
and steppes from the arid climates) and deserts (arid climates). An extra subdivision of extratropical climates into temperate and boreal climates was not possible due to limited data on boreal species. This resulted in five PFTs with sufficient trait data: tropical broadleaved deciduous and evergreen trees and extratropical broadleaved deciduous and evergreen trees and needleleaved evergreen trees. The traits used for analysis with this tree PFT classification were broadly similar to the six-PFT classification described earlier, except that there were not sufficient data to include root nitrogen content $\left(\mathrm{RNC}_{\text {mass }}\right)$ and specific root length (SRL), whereas VA and $\Psi 50$ were additionally included. In Fig. S2, the data distribution per trait is given.

\section{Kernel density estimation}

We analyzed which trait or set of traits had the highest power to discriminate between PFTs by using (Gaussian) kernel density estimation ( $k d e$ ) from the kernel smooting ('ks') package in $\mathrm{R}$ (Duong, 2014). This technique allowed estimation of probability density functions for the different PFTs within an $n$-dimensional space of traits (with $n$ varying between 1 and 6 , the latter being the maximum possible using the ' $k s$ '-package). Estimated density functions in a two-dimensional trait space are visualized in Fig. 1. For a given set of traits, we only selected species for which all selected traits were available. This resulted in sets containing a variables number of species, depending on both the selected traits as well as the number of traits. Only trait sets where at least seven species per PFT were available were tested, as seven species is the minimum number of entries needed to create a complete density kernel for a PFT within a six-dimensional trait space (and one additional species for validation). This low threshold did not

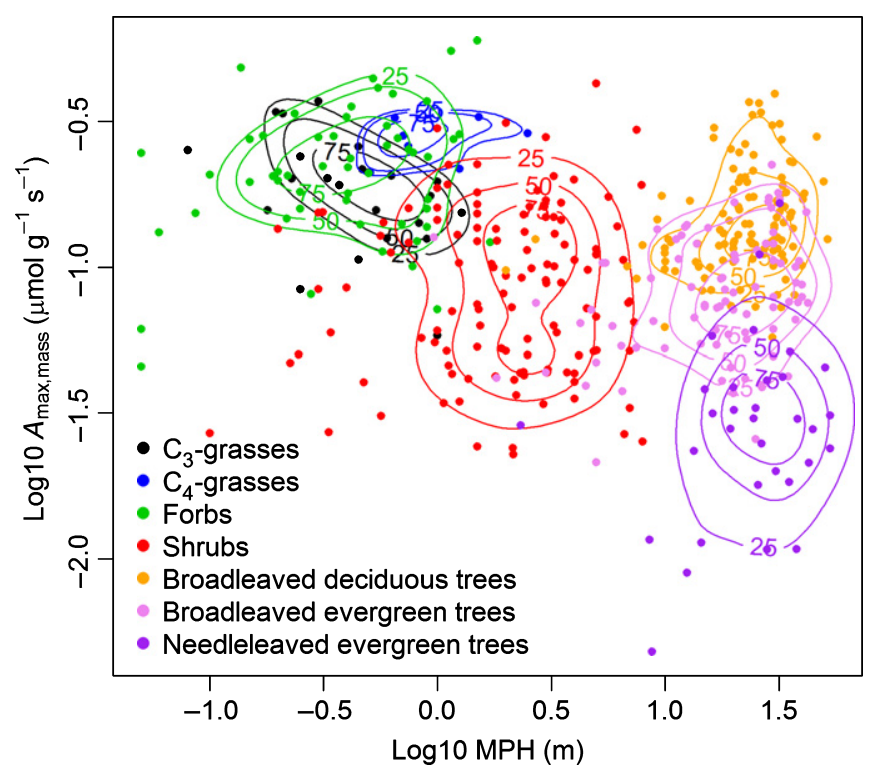

Fig. 1 Probability densities of seven plant functional types (PFTs) in a twodimensional trait-space ( $\log _{10}$-transformed maximum plant height, $M P H$, and mass-based maximum photosynthetic capacity, $A_{\max \text {,mass }}$ ). The contour lines of the different PFTs reflect upper percentages of different density regions (from inside to outside: 75,50 and $25 \%$ ). strongly affect the estimate of the probability density function (Fig. S3).

For every species within a set, the Gaussian probability density for each PFT was calculated. This calculation was based on the density kernels fitted for each PFT as constructed from the remaining data in the set (leave-one-out method). Because kernels were fitted independently across PFTs, probability densities of a given species were normalized to probabilities per PFT to enable comparisons between PFTs. To allow this normalization, probability densities were also calculated for each PFT for a dummy trait set. Normalization was obtained by dividing the species' probability density estimates for each PFT by the sum of the density estimates calculated in the dummy trait set. This unique dummy trait set was created for every trait set by evenly distributing trait values between the minimum to the maximum trait value in the dataset with a fixed number of intervals. The size of the dummy matrix (i.e. the number of dummy trait combinations) depended on the number of traits involved. Because the size of the matrix may affect model performance we did not set a fixed number of intervals. Instead, an optimal matrix size was chosen for each number of traits (see Methods S1 and Fig. S4).

Due to overlapping probability density functions of PFTs (Fig. 1), species may have probabilities larger than zero for multiple PFTs. For each species, the PFT with the highest probability was taken as the predicted PFT and compared with the observed PFT to which the species actually belonged. In this way, for each set, a so-called confusion matrix was constructed, which shows for each PFT the number of correctly classified and misclassified PFTs (e.g. Table 2). With this matrix, the fraction of correctly predicted entries per PFT was calculated ( $\left.f_{c p}\right)$, as well as the mean performance $(\overline{\mathrm{fcp}})$, the fraction of correctly categorized entries per PFT averaged over all PFTs. We used $\overline{f_{c p}}$ instead of other performance measures, such as Cohen's kappa $(\kappa)$ (Cohen, 1960) which includes a correction for the agreement caused by chance. However, $\kappa$ weighs all species equally independent of PFT identity, whereas $\overline{\mathrm{fcp}}$ gives equal weight to each PFT. This $\overline{\mathrm{fcp}}$ therefore allows the determination of the traits that lead to the highest differentiating power among PFTs, even in the presence of unbalanced data distribution across PFTs.

Most traits (except for $\mathrm{LCC}_{\text {mass }}$, SSD and $\Psi 50$ ) were log-transformed, even though the applied kde method does not demand a normal distribution of the data, but normalization of the traits by log-transformation did improve model performance.

The database was not completely filled, leading to trait sets of varying sizes. Fortunately, for the same number of traits, different dataset sizes did not significantly affect model performance except for sets with three and four traits $(P=0.040$ and 0.045 , respectively), but $R_{\text {adj }}^{2}$ were very low $\left(R_{\text {adj }}^{2}=0.021\right.$ and 0.020 , respectively) and slopes very flat (0.000027 and 0.000042 , respectively) (Fig. S5). This suggests that differences in model performance are trait-related and not much confounded by dataset size.

We also investigated whether the performance of trait sets could increase when adding traits without functional information. We tested this by adding a random, nonfunctional trait (with a similar mean and SD for all PFTs) to an existing trait set. This almost always decreased the performance of the trait set 
Table 2 Confusion matrix of mean of best performing trait sets for the seven-plant functional type (PFT) classification, with in bold the fraction correctly classified PFTs

\begin{tabular}{|c|c|c|c|c|c|c|c|}
\hline \multirow[b]{2}{*}{ Obs } & \multicolumn{7}{|l|}{ Pred } \\
\hline & $\mathrm{C}_{3}$-graminoids & $\mathrm{C}_{4}$-graminoids & Forbs & Shrubs & Bl dec trees & $\mathrm{Bl}$ ev trees & $\mathrm{Nl}$ ev trees \\
\hline $\mathrm{C}_{3}$-graminoids & 0.57 & 0.15 & 0.20 & 0.07 & 0.01 & 0.00 & 0.00 \\
\hline $\mathrm{C}_{4}$-graminoids & 0.26 & 0.53 & 0.11 & 0.10 & 0.00 & 0.00 & 0.00 \\
\hline Forbs & 0.27 & 0.10 & 0.58 & 0.04 & 0.00 & 0.00 & 0.00 \\
\hline Shrubs & 0.13 & 0.07 & 0.06 & 0.65 & 0.04 & 0.04 & 0.01 \\
\hline Bl dec trees & 0.00 & 0.00 & 0.00 & 0.04 & 0.76 & 0.18 & 0.01 \\
\hline Bl ev trees & 0.01 & 0.00 & 0.00 & 0.06 & 0.30 & 0.59 & 0.04 \\
\hline $\mathrm{Nl}$ ev trees & 0.00 & 0.00 & 0.00 & 0.07 & 0.01 & 0.06 & 0.87 \\
\hline
\end{tabular}

Obs, observed PFT; Pred, predicted PFT; Bl dec trees, broadleaved deciduous trees; Bl ev trees, broadleaved evergreen trees; NI ev trees, needleleaved evergreen trees.

(Fig. S6), suggesting that the Gaussian kernels perform appropriately in relation to nonfunctional trait additions.

\section{Results}

\section{Differentiating power of trait sets}

For the seven-PFT classification, the mean fraction of correctly predicted PFTs $\left(\overline{f_{c p}}\right)$ for each trait set was plotted against the number of traits included per trait set (Fig. 2). $\overline{\text { fcp }}$ increased with an increasing number of traits included and increased to 0.73 (with a set of five traits). From four traits onwards, trait sets did not significantly differ from each other $(P>0.85)$, whereas sets with three and six traits were not significantly different from each other either $(P=0.18)$. For sets of six traits, the predictive power decreased in comparison to sets of five traits. Although there was no clear relationship between $\overline{f_{c p}}$ and the number of species per

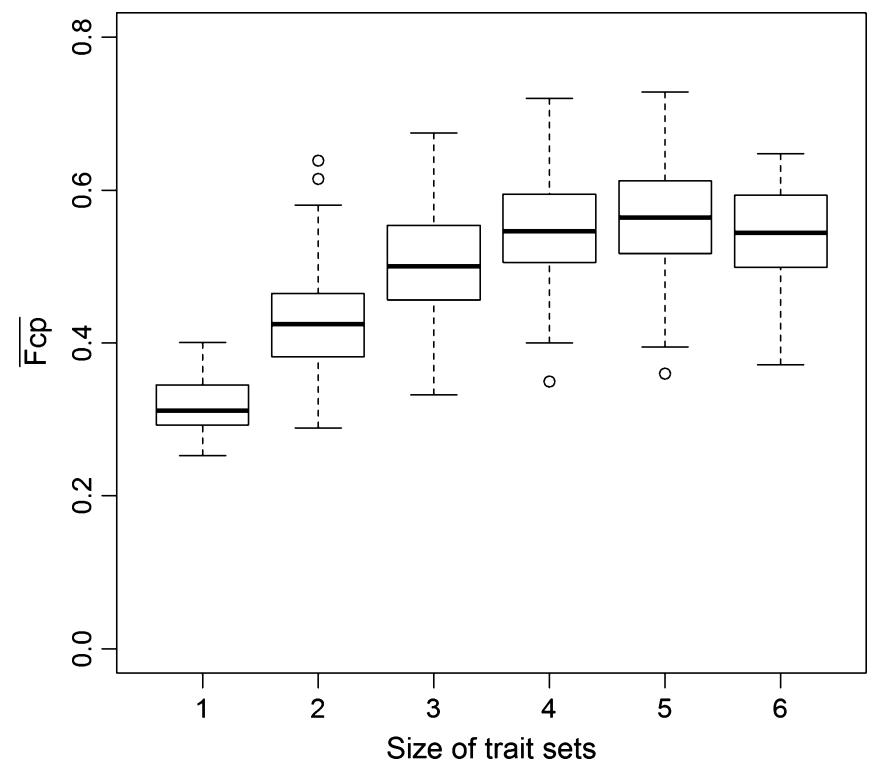

Fig. 2 Mean fraction correctly predicted $(\overline{f c p})$ of all tested trait sets against size of tested trait sets for the seven-plant functional type (PFT) classification. Box plots show the median (middle line), the 25 and $75 \%$ quartiles (hinges), the outer value within the $1.5 \times$ interquartile range (whiskers) and outliers (open circles). trait set, the number of traits that were available for six-trait sets was much lower than for the other trait sets and might have affected the performance of the six-trait sets.

\section{Predictability of PFTs in the best performing trait sets}

The $10 \%$ trait sets (for $2-6$ traits) with the highest $\overline{f_{c p}}$ ('best performing trait sets') were selected for further analyses. For seven PFTs, it comprised trait sets with a $\overline{f_{c p}}$ of $0.62-0.73$ ( $\kappa$ range 0.45-0.70): this included one two-trait set, nine three-trait sets, 22 four-trait sets, 15 five-trait sets and two six-trait sets (total of 49). The proportion of correctly predicted species, averaged per PFT (Table 2), reflecting the extent to which a PFT could be distinguished functionally from other PFTs, ranged from 0.53 for $\mathrm{C}_{4}$-graminoids to 0.87 for needleleaved evergreen trees. Although the average number of species per PFT differed among PFTs, this did not significantly affect performance of PFTs $(P=0.60)$.

$\mathrm{C}_{4}$-graminoids were correctly classified least often $(0.53)$, followed by $\mathrm{C}_{3}$-graminoids (0.57) and forbs (0.58). For both graminoids and forbs, species were only occasionally misclassified as shrubs or trees. Similarly, trees were almost never confused with herbaceous PFTs or shrubs. For the trees, needleleaved evergreen trees could be distinguished from other PFTs most reliably (0.87), followed by broadleaved deciduous trees (0.76), whereas predictability of broadleaved evergreen trees was clearly lower (0.59). Shrubs had intermediate predictability (0.65) and most misclassifications were as $\mathrm{C}_{3}$-graminoids, but shrubs were confused with any other PFT as well. Better predictability of some PFTs was not necessarily caused by a more detailed PFT definition, as reflected in less variation in trait values (Fig. S1); shrubs were the third best performing PFT (Table 2), but encompassed a wide range of species and associated trait values.

\section{Most selected traits in best performing trait sets}

Because the number of sets in which a trait occurred varied, we did not compare the absolute number of occurrences in the best performing trait sets. Instead, we compared occurrences of a trait in these best performing trait sets relative to the occurrence of a trait in the full multitrait dataset (2-6 trait sets). The trait with the highest relative occurrence was specific root length (SRL) 
(Fig. 3), but this trait occurred only seven times in the full multitrait dataset, so its actual performance in a database without gaps remains unknown. Maximum plant height (MPH) had the second highest relative occurrence (22.0\%), followed by leaf area (LA) $(18.6 \%)$. After these traits, a range of traits performed similarly well (relative occurrences between 10-15\%): minimum rooting depth (MinRD), $\mathrm{LNC}_{\text {mass}}$, mass-based leaf phosphorus content $\left(\mathrm{LPC}_{\text {mass }}\right)$, SLA and $A_{\text {max,area. }}$ Other traits had a lower occurrence than would be expected by chance $(<10 \%)$, or were never selected (stomatal conductance, $G_{\mathrm{s}}$, and mass-based root nitrogen content, $\mathrm{RNC}_{\text {mass }}$ ), although they had a low occurrence in the full multitrait dataset as well (see Table $S 1$ for occurrences of traits within 2-6-trait sets). However, other traits with low occurrences (SRL, $A_{\text {max,mass; }}$ see Table S1) did occur in the best performing trait sets, suggesting that these nonselected traits have a low differentiating ability.

\section{Co-selection of traits with maximum plant height and leaf area or leaf life span}

The high occurrence of MPH and LA in the best performing trait sets is not unexpected, because these traits are included in the

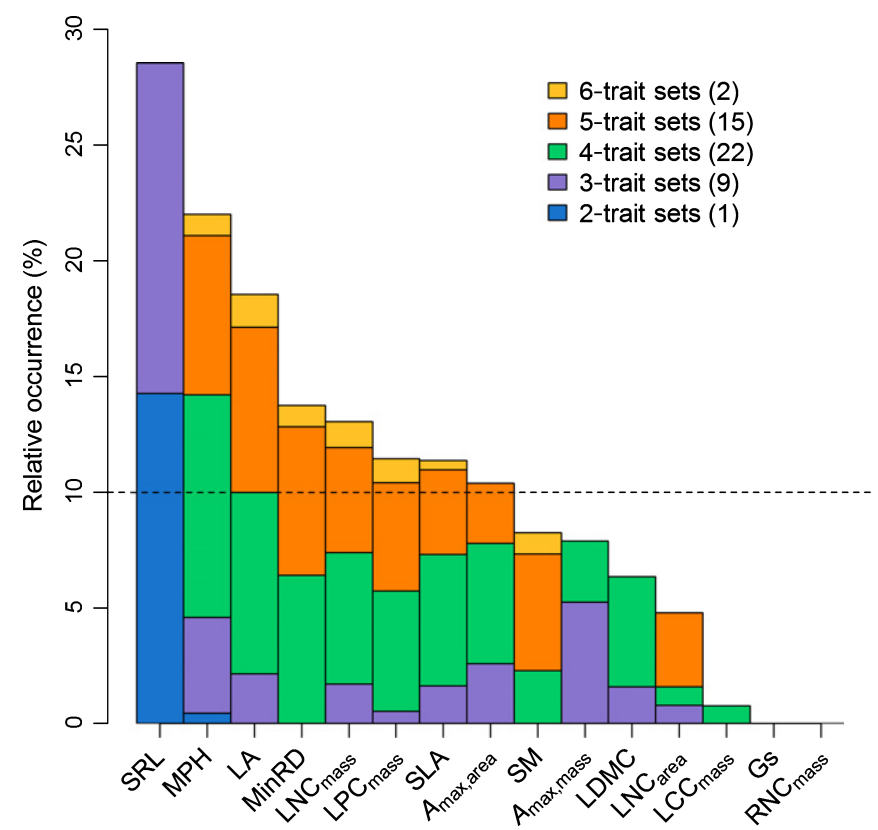

Fig. 3 Relative occurrence (\%) of traits in best performing trait sets (i.e. occurrences relative to occurrences in the full multitrait dataset) for the seven-plant functional type (PFT) classification. Colors reflect relative occurrence of traits for trait sets with different sizes. Absolute number of combinations that occurred in the best performing trait sets in brackets behind size of trait set. Dashed line indicates threshold for chance occurrences: above the line occurrences of traits are higher than by chance, below the line lower than by chance. SRL, specific root length; $M P H$, maximum plant height; LA, leaf area; MinRD, minimum rooting

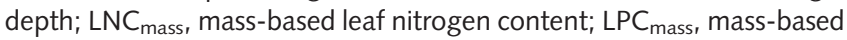
leaf phosphorus content; SLA, specific leaf area; $A_{\text {max, arear }}$ area-based maximum photosynthetic rate; $S M$, seed mass; $A_{\text {max, mass, }}$ mass-based maximum photosynthetic rate; $L D M C$, leaf dry matter content; $L N C_{\text {area }}$ area-based leaf nitrogen content; $L C C_{\text {mass }}$ mass-based leaf carbon

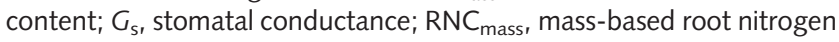
content. definition of PFTs (e.g. MPH distinguishes trees from the other PFTs, and LA separates broadleaved from needleleaved trees). Therefore, including these two traits is likely to increase the chance of achieving a high $\overline{\mathrm{fcp}}$. Looking at the traits that were selected together with these two traits can reveal which traits add additional functional information. From the 49 best performing trait sets in the seven-PFT classification, 26 trait combinations (53.1\%), contained both MPH and LA. Traits that occurred with these two traits more often than what would be expected by chance alone (i.e. occurrence of $>53.1 \%$ ) were SM (13 times, which is $72.2 \%$ of its occurrences in the best performing trait sets), followed by $\mathrm{LNC}_{\text {area }}$ (four times, 66.7\%), MinRD (nine times, 60\%) and $\mathrm{LPC}_{\text {mass }}$ (13 times, 59.1\%) (Fig. 4), whereas other traits had lower occurrences than $53.1 \%$, or did not occur at all in combination with MPH and LA.

\section{Six-PFT classification performance}

When merging $\mathrm{C}_{3}$ - and $\mathrm{C}_{4}$-graminoids, resulting in a six-PFT classification, $\overline{f_{c p}}$ increased to 0.85 (Fig. S7) and $\kappa$ increased to 0.79 , meaning that performance increased even when corrected for chance effects. The $\overline{f c p}$ of the best performing trait sets (240 sets) ranged from 0.69 to 0.85 ( $\kappa$ range $0.51-0.79$ ). The confusion matrix for this classification (Table S2) was broadly similar to that for the seven-PFT analysis.

The traits with the highest relative occurrence in the best performing trait sets was (again) MPH (22.0\%), followed by traits

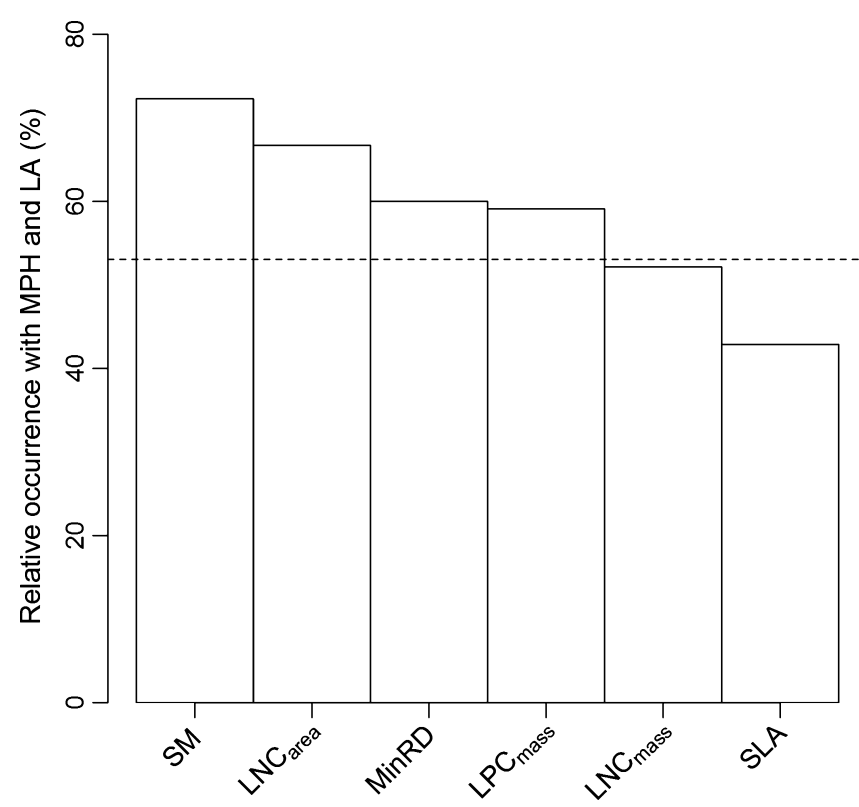

Fig. 4 Relative occurrence of traits (\%) together with maximum plant height (MPH) and leaf area (LA) in the best performing trait sets (i.e. occurrences of traits with $\mathrm{MPH}$ and LA in best performing trait sets relative to occurrences of traits in all best performing trait sets) for the seven-plant functional type (PFT) classification. Dashed line indicates threshold for chance occurrences: above the line occurrences of traits are higher than by chance, below the line lower than by chance. SM, seed mass; $L_{N C_{\text {area }}}$ area-based leaf nitrogen content; MinRD, minimum rooting depth; $\mathrm{LPC}_{\text {mass }}$, mass-based leaf phosphorus content; $\mathrm{LNC}_{\text {mass, }}$ mass-based leaf nitrogen content; SLA, specific leaf area. 
that were not present in the seven-PFT classification: LLS (relative occurrence of 19.5\%), and SSD (17\%) (Fig. S8). Traits with a relative occurrence between 15 and $10 \%$ included again a number of leaf traits (LA, $\mathrm{LNC}_{\text {mass }}$ and SLA) and MinRD.

Only $20 \%$ of the 240 best performing trait sets contained both $\mathrm{MPH}$ and LA (48 sets). The traits that were co-selected more often than expected by chance with these traits were MinRD and $\mathrm{LPC}_{\text {mass }}$ (27.0 and 22.6\%, respectively) as in the seven-PFT classification, but also SSD (24.5\%) (Fig. S9). By contrast, SM and $\mathrm{LNC}_{\text {area }}$ were no longer selected more often than expected by chance. Like MPH and LA, LLS is also part of the PFT-definition (for trees), suggesting that LLS will also have a high differentiating power. Indeed, 107 combinations out of the 240 best performing trait combinations $(44.6 \%)$ contained LLS and MPH. Traits which had a higher occurrence than expected by chance (44.6\%) were $A_{\text {max,mass }}$ and $\mathrm{LNC}_{\text {area }}$ (60.5 and $50.8 \%$, respectively), whereas in contrast to traits associated with $\mathrm{MPH}$ and LA, MinRD and SSD were selected less often.

\section{Bioclimatic tree classification}

For classifications with trees only, as separated into extratropical and tropical trees, $\overline{\mathrm{fcp}}$ ranged from 0.68 to 0.80 ( $\kappa$ range 0.44 0.77 ) in the best $10 \%$ performing trait sets (302 trait sets). Because the tree PFT classification comprised five PFTs, the fraction correctly predicted averaged per PFT was expected to increase by $3.3 \%$ to $5.7 \%$ by chance alone. However, the percentage correctly predicted increased only for the tropical and extratropical broadleaved evergreen trees (by $7-10 \%$ and $13-16 \%$, respectively) (Table S3), suggesting that traits are less effective at distinguishing among bioclimatic classifications than growth forms.

In the best performing trait sets, LLS appeared to be the dominant trait (Fig. 5). By comparing different tree PFTs with each other, height as a major determinant of growth form was removed, but MPH was still selected, although less often than in the seven and six PFT classification analyses. In contrast to these PFT classifications, traits directly related to carbon assimilation and release, $A_{\text {max,mass }}, A_{\text {maxx,area }}, G_{\mathrm{s}}$ and $\mathrm{Rd}_{\text {mass }}$ were much more frequently selected in the tree PFT classification. By contrast, traits that did well in the general PFT classifications, like MinRD and SSD, were not often selected to distinguish among tree PFTs. The additional traits, $\Psi 50$ and VA, did not occur very often either, but this can be due to the fact that they occurred in a lower number of trait sets. Looking at trait associations with LLS, the traits that were co-selected more often than expected by chance $(81.5 \%)$ with LLS were $\Psi 50$ (100\%, but occurring only once in the best $10 \%$ dataset), $\mathrm{LNC}_{\text {area }}(98.5 \%) A_{\text {max,mass }}$ $(93.3 \%)$ and $\operatorname{Rd}_{\text {mass }}(87.1 \%)$, followed by $G_{s}(85.9 \%)$ and SSD (85.3\%) (Fig. S10).

\section{Discussion}

\section{Functional dissimilarity of PFTs}

Many studies describe which traits are considered important in distinguishing between different plant ecological strategies

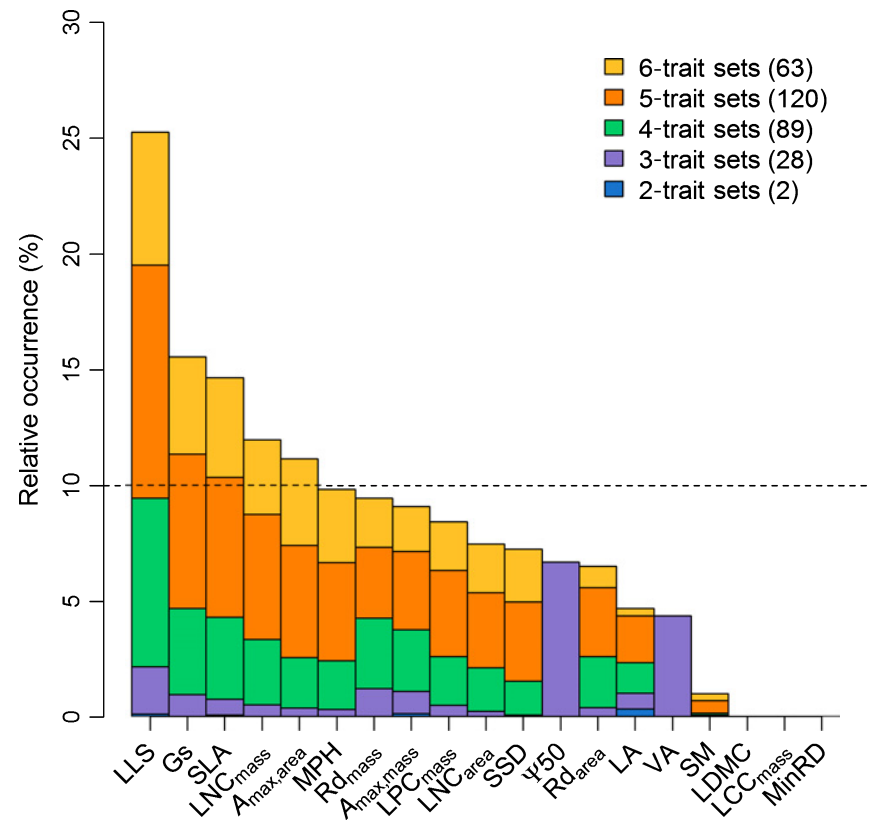

Fig. 5 Relative occurrence (\%) of traits in best performing trait sets (i.e. occurrences relative to occurrences in the full multi-trait dataset) for the tree plant functional type (PFT) classification. Colors reflect relative occurrence of traits for trait sets with different sizes. In brackets behind size of trait set, absolute number of combinations that occurred in the best performing trait sets. Dashed line indicates threshold for chance occurrences: above the line occurrences of traits are higher than by chance, below the line lower than by chance. LLS, leaf life span; $G_{s}$ stomatal conductance; SLA, specific leaf area; $L N C_{\text {mass, }}$ mass-based leaf nitrogen content; $A_{\text {max,arear }}$ area-based maximum photosynthetic rate; $\mathrm{MPH}$, maximum plant height; $\mathrm{Rd}_{\text {mass, }}$ mass-based leaf dark respiration; $A_{\text {max,mass, }}$ mass-based maximum photosynthetic rate; $\mathrm{LPC}_{\text {mass, }}$ massbased leaf phosphorus content; $\mathrm{LNC}_{\text {arear }}$, area-based leaf nitrogen content; SSD, specific stem density; $\Psi 50$, water potential at which $50 \%$ loss of conductivity occurs; $\mathrm{Rd}_{\text {arear }}$ area-based leaf dark respiration; $\mathrm{LA}$, leaf area; $V A$, vessel area; SM, seed mass; LDMC, leaf dry matter content; LCC $_{\text {mass, }}$ mass-based leaf carbon content; MinRD, minimum rooting depth.

(Westoby, 1998; Weiher et al., 1999), but different plant strategies are not restricted to specific PFTs. PFTs can include multiple plant strategies and plant strategies can overlap between PFTs as well, as is reflected by the large variation in trait values observed within PFTs and the overlap in trait values between PFTs (Kattge etal., 2011; Van Bodegom etal., 2012; Verheijen etal., 2013). Here, we quantitatively determined to what extent plant traits can distinguish between predefined, growth form-based PFTs and which trait sets are most likely to produce a model with a high differentiating ability. We show that despite overlap in plant strategies within and between PFTs, traits are a powerful tool to distinguish between PFTs. In our study, four to five traits were found to be sufficient to classify PFTs correctly up to $85 \%$ ( $\kappa$ of 0.79 , for six PFTs), without the need for any additional constraint. This high percentage indicates that although PFTs might overlap in single trait values and plant strategies, the kernel density estimation method shows their different positioning in multidimensional trait-space. This different positioning of PFTs reflects, at least in part, functional differentiation across several strategy axes. Our study therefore quantitatively demonstrates 
that structural properties of plants (growth form, leaf shape, leaf phenology) also reflect functional differences.

\section{Correlated traits still have differentiating ability}

Some traits were selected more often than others in the best performing trait sets of the different PFT classifications. As expected, traits that are reflected in the definitions of the PFTs, such as MPH, LA and LLS, appeared most often in the best performing traits sets of the seven- and six-PFT classifications. Because PFTs differ more in terms of LLS than of LA (Fig. S1), LLS replaced $\mathrm{LA}$ as an important distinguishing trait, as soon as it was included in the six PFT classification (Fig. S8). MPH also occurred in the tree PFT classification, suggesting that height still plays a role in distinguishing among different types of trees, even though Moles et al. (2009) did not find latitudinal gradients in plant height within trees.

A range of other traits can be combined with $\mathrm{MPH}$ and either LA or LLS and provide additional information on the functions that relate to different growth forms and associated PFTs. This trait selection is dependent on the PFT classification, but overall, combining MinRD and either SM or SSD with these traits, as well as an additional leaf trait, either $\mathrm{LNC}_{\text {area }}, \mathrm{LPC}_{\text {mass }}$ or $A_{\text {max,mass }}$, increases the chances of obtaining a trait set with a high differentiating ability between PFTs.

Although we expected that sets of traits combining different functional aspects within plants would capture functional differences between PFTs best and consequently would have the highest differentiating power, this is only partly true and trait combinations that are considered functionally redundant because they relate to similar strategy axes, for example the 'leaf economics traits' like LA, LLS, SLA, LPC or LNC, or that are involved in a trade-off with each other, like MPH and SM, MinRD or SSD, are included in the best performing trait sets as well.

This inclusion of correlated traits may be due to a number of reasons. First, because PFTs include a variety of plant strategies, these traits might be selected in combination to reflect the multiple plant strategies within a PFT. In that case, PFTs can be differentiated from each other because each PFT represents a different combination of plant strategies.

Alternatively, although not excluding the first explanation, the co-selection of correlated traits might also indicate that within a given trade-off or strategy axis, trait variation is still possible. It is known that trade-offs limit the occurrence of certain combinations of trait values due to mechanistic or physiological limitations. However, it seems that within certain trade-offs, multiple trait value combinations can still occur, reflecting alternative solutions within a strategy with about equal fitness (Marks \& Lechowicz, 2006). According to this explanation, different PFTs express different (sets of) alternative solutions within a plant strategy.

For example, variation in SM, MinRD and SSD is restricted because of trade-offs between these traits and MPH: large plants need a minimum stem specific density and rooting depth to mechanistically sustain a certain height (Schenk \& Jackson, 2002b; Chave et al., 2009). In addition, small plants are unlikely to bear very large and heavy seeds (Moles et al., 2004). However, despite these trade-offs, SM, MinRD and SSD were selected with $\mathrm{MPH}$ more often than expected by chance. This could mean that for a given MPH, different PFTs have different solutions to deal with (and partly avoid) these trade-offs and thus make different choices with respect to for example dispersal strategies (SM) (Westoby et al., 2002; Moles \& Westoby, 2004; Moles et al., 2004), water transport, cavitation resistance or resistance against disturbances (SSD) (Westoby \& Wright, 2006; Chave et al., 2009) or water availability (MinRD) (Schenk \& Jackson, 2002a, b).

As another example, needleleaved evergreen trees (consisting exclusively of gymnosperms in our dataset), largely overlap in MPH and completely overlap in SM and SSD with the other tree PFTs (Fig. S1). However, the different vessel anatomy of gymnosperms and angiosperms (Chave et al., 2009) allows for a lower SSD for a given MPH for needleleaved evergreen trees. In addition, there seems to be a different trade-off between SM and height, resulting in a different relationship between these traits for gymnosperms (Moles et al., 2004), that might allow differentiation of this PFT from others based on MPH and SM. Thus, consideration of the different choices of PFTs among the various functions and related traits is therefore essential to better understand the functioning of growth form-related PFTs.

\section{Towards further improvements of traits-based classifications}

Misclassifications of PFTs occurred mostly between closely related growth forms, such as within trees or within herbs (graminoids and forbs), whereas shrubs showed functional overlap with both trees and herbs. Overlap in sets of traits between PFTs could mean that there is functional similarity between PFTs, although the high percentage correctly predicted PFTs show that structural aspects of plants indeed also reflect functional differences to a large extent. Alternatively, overlap could mean that functional differences are not completely distinguished by the traits chosen. For example, through the six-PFT classification we could add a number of traits (LLS, SSD and $\mathrm{Rd}_{\text {mass }}$ and $\mathrm{Rd}_{\text {area }}$ ) to the trait sets that were not possible for the seven PFT classification due to data limitations. The inclusion of these traits resulted in a better separation of broadleaved evergreen trees from broadleaved deciduous trees (7-9\% fewer misclassifications between these two PFTs; see Tables 2, S2) and a better separation of shrubs from graminoids. Additionally, other traits that were not yet available for a large number of species, but are known to have strong functional implications, might further improve PFT classifications. For example, traits related to tolerances to bioclimatic conditions such as cold tolerance thresholds of different organs or survival thresholds (Woodward \& Kelly, 1997; Harrison et al., 2010), or disturbances like fire (reflected by e.g. bark thickness; Hoffmann et al., 2003) might increase the predictive ability of traits. $\mathrm{C}_{4}$-graminoids and $\mathrm{C}_{3}$-graminoids might be better distinguished from each other when, for example, such cold-tolerance related traits are included, because $\mathrm{C}_{3}$-grasses 
occur in colder climates than $\mathrm{C}_{4}$-grasses, even though this is not true for all $\mathrm{C}_{3}$-lineages (Edwards \& Smith, 2010).

Gaps in our dataset also hampered the testing trait of combinations that may be fruitful. For instance, single trait performances (Tables S4, S5 for the seven- and six-PFT classifications, respectively) suggested that for a seven-PFT classification, a combination of leaf dry matter content (LDMC), $\mathrm{SM}, \mathrm{RNC}_{\text {mass, }}$, MinRD, and either $A_{\text {max,mass }}$ or $\mathrm{LNC}_{\text {mass }}$ might result in a high performing model. For the six-PFT classification this would be LLS, MinRD, LDMC and $\mathrm{Rd}_{\text {mass. }}$. Interestingly, this would mean that MPH would not necessarily be included, but currently, data gaps prevented testing these potentially important sets. In addition, some traits with low data coverage are potentially interesting for further extensions of our approach, either because they had a high relative occurrence (SRL) or due to a strong association with LLS ( $\Psi 50)$. Again, data limitations currently hampered making generalizations about their actual performance. Therefore, increasing the number of trait data per species is an important next step to take.

\section{Implications}

Only a limited number of strategy axes with related traits $(\mathrm{MPH}$, SM, SLA) are typically used to distinguish between different plant strategies (Westoby, 1998; Diaz et al., 2004). Our analysis shows that traits related to the same strategy axis or traits involved in trade-offs with each other, still add functional information about and allow discrimination between sets of plant strategies as reflected by PFTs. Therefore, although current plant ecology strategy schemes help to theoretically understand differences in the ecological behavior of plants and have identified some main traits important in plant functioning, our analysis provides new insights into how functional differences of different growth-form based PFTs are shaped by traits. Defining a priori the most important traits while excluding correlated traits in advance will result in a loss of differentiating capacity and consequently hamper further functional understanding. This is illustrated by a regional study that investigated which traits are needed to distinguish existing vegetation types. The analysis showed that the two or three categories used in most plant strategy schemes were insufficient to capture functional differences because they put nonredundant traits into a single category (Douma et al., 2012a).

When this potential of plant traits to functionally differentiate among PFTs is acknowledged, traits can be a powerful tool for predictive ecology. The impacts of climate change on vegetation distribution can be investigated, by predicting changes in vegetation distribution based on plant traits. The PFT analysis for trees shows that trait combinations can also be used to distinguish between bioclimatically defined PFTs, enabling the differentiation among responses of tropical and extratropical (and likely also between boreal and temperate) vegetation. Van Bodegom et al. (2014) previously showed how vegetation maps may be constructed based on global trait maps. This vegetation map predicted a similar vegetation distribution to vegetation maps that were modeled by global dynamic vegetation models (DGVMs). In our analysis, multiple combinations of traits had a similar ability to distinguish between vegetation types. Hence, the results of this study can be used to choose those traits that have the strongest relationsip to environmental conditions in order to optimize our abilities to predict vegetation distribution, with major implications for predictive vegetation modeling.

\section{Acknowledgements}

This study has been financed by the Netherlands Organization for Scientific Research (NWO), Theme Sustainable Earth Research (project number TKS09-03) and has been supported by the TRY initiative on plant traits (http://www.try-db.org). TRY is currently supported by DIVERSITAS/Future Earth and the German Centre for Integrative Biodiversity Research (iDiv) Halle-Jena-Leipzig. The authors would also like to thank Paul Torfs from Wageningen University for his help with kernel density estimation in $\mathrm{R}$.

\section{References}

Ackerly DD, Cornwell WK. 2007. A trait-based approach to community assembly: partitioning of species trait values into within- and amongcommunity components. Ecology Letters 10: 135-145.

Bahn M, Wohlfahrt G, Haubner E, Horak I, Michaeler W, Rottmar K, Tappeiner U, Cernusca A. 1999. Leaf photosynthesis, nitrogen contents and specific leaf area of 30 grassland species in differently managed mountain ecosystems in the Eastern Alps. In: Cernusca A, Tappeiner U, Bayfield N, eds. Land-use changes in European mountain ecosystems. ECOMONT-concept and results. Berlin, Germany: Blackwell Wissenschaft, 247-255.

Baker TR, Phillips OL, Laurance WF, Pitman NCA, Almeida S, Arroyo L, DiFiore A, Erwin T, Higuchi N, Killeen TJ et al. 2009. Do species traits determine patterns of wood production in Amazonian forests? Biogeosciences 6 : 297-307.

Bakker C, Van Bodegom PM, Nelissen HJM, Ernst WHO, Aerts R. 2006. Plant responses to rising water tables and nutrient management in calcareous dune slacks. Plant Ecology 185: 19-28.

Blanco CC, Sosinski EE Jr, dos Santos BRC, da Silva MA, Pillar VD. 2007. On the overlap between effect and response plant functional types linked to grazing. Community Ecology 8: 57-65.

Boulangeat I, Philippe P, Abdulhak S, Douzet R, Garraud L, Lavergne S, Lavorel S, Van Es J, Vittoz P, Thuiller W. 2012. Improving plant functional groups for dynamic models of biodiversity: at the crossroads between functional and community ecology. Global Change Biology 18: 3464-3475.

Box EO. 1996. Plant functional types and climate at the global scale. Journal of Vegetation Science 7: 309-320.

Campbell C, Atkinson L, Zaragoza-Castells J, Lundmark M, Atkin O, Hurry V. 2007. Acclimation of photosynthesis and respiration is asynchronous in response to changes in temperature regardless of plant functional group. New Phytologist 176: 375-389.

Cavender-Bares J, Keen A, Miles B. 2006. Phylogenetic structure of Floridian plant communities depends on taxonomic and spatial scale. Ecology 87: S109S122.

Chamberlain S, Ram K, Barve V, Mcglinn D. 2014. RGBIF: interface to the Global Biodiversity Information Facility API. R package version 0.7.0. [WWW document] URL http://CRAN.R-project.org/package=rgbif [accessed 29 September 2014].

Chave J, Coomes D, Jansen S, Lewis SL, Swenson NG, Zanne AE. 2009. Towards a worldwide wood economics spectrum. Ecology Letters 12: 351-366.

Choat B, Jansen S, Brodribb TJ, Cochard H, Delzon S, Bhaskar R, Bucci SJ, Feild TS, Gleason SM, Hacke UG et al. 2012. Global convergence in the vulnerability of forests to drought. Nature 491: 752-756.

Cohen J. 1960. A coefficient of agreement for nominal scales. Educational and Psychological Measurement 20: 37-46. 
Comas LH, Eissenstat DM. 2004. Linking fine root traits to maximum potential growth rate among 11 mature temperate tree species. Functional Ecology 18: 388-397.

Comas LH, Eissenstat DM. 2009. Patterns in root trait variation among 25 coexisting North American forest species. New Phytologist 182: 919-928.

Cornelissen JHC. 1996. An experimental comparison of leaf decomposition rates in a wide range of temperate plant species and types. Journal of Ecology 84: 573-582.

Cornelissen JHC, Cerabolini B, Castro-Diez P, Villar-Salvador P, MontserratMarti G, Puyravaud JP, Maestro M, Werger MJA, Aerts R. 2003a. Functional traits of woody plants: correspondence of species rankings between field adults and laboratory-grown seedlings? Journal of Vegetation Science 14: 311-322.

Cornelissen JHC, Diez PC, Hunt R. 1996. Seedling growth, allocation and leaf attributes in a wide range of woody plant species and types. Journal of Ecology 84: 755-765.

Cornelissen JHC, Lavorel S, Garnier E, Diaz S, Buchmann N, Gurvich DE, Reich PB, ter Steege H, Morgan HD, Van der Heijden MGA et al. 2003b. A handbook of protocols for standardised and easy measurement of plant functional traits worldwide. Australian Journal of Botany 51: 335-380.

Cornelissen JHC, Quested HM, Gwynn-Jones D, Van Logtestijn RSP, De Beus MAH, Kondratchuk A, Callaghan TV, Aerts R. 2004. Leaf digestibility and litter decomposability are related in a wide range of subarctic plant species and types. Functional Ecology 18: 779-786.

Cornelissen JHC, Werger MJA, CastroDiez P, vanRheenen JWA, Rowland AP. 1997. Foliar nutrients in relation to growth, allocation and leaf traits in seedlings of a wide range of woody plant species and types. Oecologia 111: 460-469.

Cornwell WK, Schwilk DW, Ackerly DD. 2006. A trait-based test for habitat filtering: convex hull volume. Ecology 87: 1465-1471.

Craine JM, Elmore AJ, Aidar MPM, Bustamante M, Dawson TE, Hobbie EA, Kahmen A, Mack MC, McLauchlan KK, Michelsen A et al. 2009. Global patterns of foliar nitrogen isotopes and their relationships with climate, mycorrhizal fungi, foliar nutrient concentrations, and nitrogen availability. New Phytologist 183: 980-992.

Craine JM, Froehle J, Tilman GD, Wedin DA, Chapin FS. 2001. The relationships among root and leaf traits of 76 grassland species and relative abundance along fertility and disturbance gradients. Oikos 93: 274-285.

Craine JM, Lee WG. 2003. Covariation in leaf and root traits for native and nonnative grasses along an altitudinal gradient in New Zealand. Oecologia 134: 471-478.

Craine JM, Lee WG, Bond WJ, Williams RJ, Johnson LC. 2005. Environmental constraints on a global relationship among leaf and root traits of grasses. Ecology 86: $12-19$.

Diaz S, Cabido M. 1997. Plant functional types and ecosystem function in relation to global change. Journal of Vegetation Science 8: 463-474.

Diaz S, Hodgson JG, Thompson K, Cabido M, Cornelissen JHC, Jalili A, Montserrat-Marti G, Grime JP, Zarrinkamar F, Asri Y et al. 2004. The plant traits that drive ecosystems: evidence from three continents. Journal of Vegetation Science 15: 295-304.

Douma JC, Aerts R, Witte JPM, Bekker RM, Kunzmann D, Metselaar K, Van Bodegom PM. 2012a. A combination of functionally different plant traits provides a means to quantitatively predict a broad range of species assemblages in NW Europe. Ecography 35: 364-373.

Douma JC, Bardin V, Bartholomeus RP, Van Bodegom PM. 2012b. Quantifying the functional responses of vegetation to drought and oxygen stress in temperate ecosystems. Functional Ecology 26: 1355-1365.

Duarte LdS, Carlucci MB, Hartz SM, Pillar VD. 2007. Plant dispersal strategies and the colonization of Araucaria forest patches in a grassland-forest mosaic. Journal of Vegetation Science 18: 847-858.

Duong T. 2014. ks: Kernel smoothing. R package version 1.9.3. [WWW document] URL http://cran.r-project.org/web/packages/ks/ks.pdf [accessed 25 September 2014].

Edwards EJ, Smith SA. 2010. Phylogenetic analyses reveal the shady history of $\mathrm{C}_{4}$ grasses. Proceedings of the National Academy of Sciences, USA 107: 25322537.

Fonseca CR, Overton JM, Collins B, Westoby M. 2000. Shifts in traitcombinations along rainfall and phosphorus gradients. Journal of Ecology 88: 964-977.
Fort F, Jouany C, Cruz P. 2013. Root and leaf functional trait relations in Poaceae species: implications of differing resource-acquisition strategies. Journal of Plant Ecology 6: 211-219.

Fortunel C, Garnier E, Joffre R, Kazakou E, Quested H, Grigulis K, Lavorel S, Ansquer P, Castro H, Cruz P et al. 2009. Leaf traits capture the effects of land use changes and climate on litter decomposability of grasslands across Europe. Ecology 90: 598-611.

Freschet GT, Cornelissen JHC, Van Logtestijn RSP, Aerts R. 2010a. Evidence of the 'plant economics spectrum' in a subarctic flora. Journal of Ecology 98: 362-373.

Freschet GT, Cornelissen JHC, Van Logtestijn RSP, Aerts R. 2010b. Substantial nutrient resorption from leaves, stems and roots in a subarctic flora: what is the link with other resource economics traits? New Phytologist 186: 879-889.

Fyllas NM, Patino S, Baker TR, Nardoto GB, Martinelli LA, Quesada CA, Paiva R, Schwarz M, Horna V, Mercado LM et al. 2009. Basin-wide variations in foliar properties of Amazonian forest: phylogeny, soils and climate. Biogeosciences 6: 2677-2708.

Green W. 2009. USDA PLANTS compilation, version 1 09-02-02. [WWW document] URL http://bricol.net/downloads/data/PLANTSdatabase/ [accessed 6 August 2014].

Han WX, Fang JY, Guo DL, Zhang Y. 2005. Leaf nitrogen and phosphorus stoichiometry across 753 terrestrial plant species in China. New Phytologist 168: 377-385.

Harrison SP, Prentice IC, Barboni D, Kohfeld KE, Ni J, Sutra J-P. 2010. Ecophysiological and bioclimatic foundations for a global plant functional classification. Journal of Vegetation Science 21: 300-317.

He J-S, Wang L, Flynn DFB, Wang X, Ma W, Fang J. 2008. Leaf nitrogen: phosphorus stoichiometry across Chinese grassland biomes. Oecologia 155: 301-310

He JS, Wang ZH, Wang XP, Schmid B, Zuo WY, Zhou M, Zheng CY, Wang MF, Fang JY. 2006. A test of the generality of leaf trait relationships on the Tibetan Plateau. New Phytologist 170: 835-848.

Hendricks JJ, Aber JD, Nadelhoffer KJ, Hallett RD. 2000. Nitrogen controls on fine root substrate quality in temperate forest ecosystems. Ecosystems 3: 57 69.

Hoffmann WA, Orthen B, Do Nascimento PKV. 2003. Comparative fire ecology of tropical savanna and forest trees. Functional Ecology 17: 720-726.

Holdaway RJ, Richardson SJ, Dickie IA, Peltzer DA, Coomes DA. 2011. Species- and community-level patterns in fine root traits along a 120000 -year soil chronosequence in temperate rain forest. Journal of Ecology 99: 954-963.

Kattge J, Diaz S, Lavorel S, Prentice C, Leadley P, Boenisch G, Garnier E, Westoby M, Reich PB, Wright IJ et al. 2011. TRY - a global database of plant traits. Global Change Biology 17: 2905-2935.

Kattge J, Knorr W, Raddatz T, Wirth C. 2009. Quantifying photosynthetic capacity and its relationship to leaf nitrogen content for global-scale terrestrial biosphere models. Global Change Biology 15: 976-991.

Kazakou E, Vile D, Shipley B, Gallet C, Garnier E. 2006. Co-variations in litter decomposition, leaf traits and plant growth in species from a Mediterranean old-field succession. Functional Ecology 20: 21-30.

Kerkhoff AJ, Fagan WF, Elser JJ, Enquist BJ. 2006. Phylogenetic and growth form variation in the scaling of nitrogen and phosphorus in the seed plants. American Naturalist 168: E103-E122.

Kirkup D, Malcolm P, Christian G, Paton A. 2005. Towards a digital African Flora. Taxon 54: 457-466.

Kleyer M, Bekker RM, Knevel IC, Bakker JP, Thompson K, Sonnenschein M, Poschlod P, Van Groenendael JM, Klimeš L, Klimešová J et al. 2008. The LEDA Traitbase: a database of life-history traits of the Northwest European flora. Journal of Ecology 96: 1266-1274.

Klotz S, Kühn I, Durka W. 2002. BIOLFLOR - Eine Datenbank mit biologisch-ö kologischen Merkmalen zur Flora von Deutschland. Schriftenreihe für Vegetationskunde 38. Bonn, Germany: Bundesamt für Naturschutz.

Kottek M, Grieser J, Beck C, Rudolf B, Rubel F. 2006. World map of the Köppen-Geiger climate classification updated. Meteorologische Zeitschrift 15: 259-263.

Kurokawa H, Nakashizuka T. 2008. Leaf herbivory and decomposability in a Malaysian tropical rain forest. Ecology 89: 2645-2656. 
Laughlin DC, Leppert JJ, Moore MM, Sieg CH. 2010. A multi-trait test of the leaf-height-seed plant strategy scheme with 133 species from a pine forest flora. Functional Ecology 24: 493-501.

Laughlin DC, Moore MM. 2009. Climate-induced temporal variation in the productivity-diversity relationship. Oikos 118: 897-902.

Lavorel S, Diaz S, Cornelissen JHC, Garnier E, Harrison SP, McIntyre S, Pausas JG, Pérez-Harguindeguy N, Roumet C, Urcelay C. 2007. Plant functional types: are we getting any closer to the Holy Grail? In: Canadell JG, Pataki DE, Pitelka LF, eds. Terrestrial ecosystems in a changing world. Heidelberg, Germany: Springer, 149-160.

Lavorel S, Garnier E. 2002. Predicting changes in community composition and ecosystem functioning from plant traits: revisiting the Holy Grail. Functional Ecology 16: 545-556.

Lavorel S, McIntyre S, Landsberg J, Forbes TDA. 1997. Plant functional classifications: from general groups to specific groups based on response to disturbance. Trends in Ecology \& Evolution 12: 474-478.

Leishman MR, Westoby M. 1992. Classifying plants into groups on the basis of associations of indivdual traits - evidence from Australian semi-arid woodlands. Journal of Ecology 80: 417-424.

Liu G, Freschet GT, Pan X, Cornelissen JHC, Li Y, Dong M. 2010. Coordinated variation in leaf and root traits across multiple spatial scales in Chinese semi-arid and arid ecosystems. New Phytologist 188: 543-553.

Lloyd J, Bloomfield K, Domingues TF, Farquhar GD. 2013. Photosynthetically relevant foliar traits correlating better on a mass vs an area basis: of ecophysiological relevance or just a case of mathematical imperatives and statistical quicksand? New Phytologist 199: 311-321.

Louault F, Pillar VD, Aufrere J, Garnier E, Soussana JF. 2005. Plant traits and functional types in response to reduced disturbance in a semi-natural grassland. Journal of Vegetation Science 16: 151-160.

Loveys BR, Atkinson LJ, Sherlock DJ, Roberts RL, Fitter AH, Atkin OK. 2003. Thermal acclimation of leaf and root respiration: an investigation comparing inherently fast- and slow-growing plant species. Global Change Biology 9: 895910.

Marks CO, Lechowicz MJ. 2006. Alternative designs and the evolution of functional diversity. American Naturalist 167: 55-66.

McCormack ML, Adams TS, Smithwick EAH, Eissenstat DM. 2012. Predicting fine root lifespan from plant functional traits in temperate trees. New Phytologist 195: 823-831.

Medlyn BE, Badeck FW, De Pury DGG, Barton CVM, Broadmeadow M, Ceulemans R, De Angelis P, Forstreuter M, Jach ME, Kellomaki $S$ et al. 1999. Effects of elevated $\mathrm{CO}_{2}$ on photosynthesis in European forest species: a meta-analysis of model parameters. Plant, Cell \& Environment 22: $1475-1495$.

Medlyn BE, Barton CVM, Broadmeadow MSJ, Ceulemans R, De Angelis P, Forstreuter M, Freeman M, Jackson SB, Kellomaki S, Laitat E et al. 2001. Stomatal conductance of forest species after long-term exposure to elevated $\mathrm{CO}_{2}$ concentration: a synthesis. New Phytologist 149: 247-264.

Medlyn BE, Jarvis PG. 1999. Design and use of a database of model parameters from elevated $\mathrm{CO}_{2}$ experiments. Ecological Modelling 124: 69-83.

Messier J, McGill BJ, Lechowicz MJ. 2010. How do traits vary across ecological scales? A case for trait-based ecology. Ecology Letters 13: 838-848.

Meziane D, Shipley B. 1999. Interacting determinants of specific leaf area in 22 herbaceous species: effects of irradiance and nutrient availability. Plant, Cell \& Environment 22: 447-459.

Moles AT, Ackerly DD, Webb CO, Tweddle JC, Dickie JB, Westoby M. 2005. A brief history of seed size. Science 307: 576-580.

Moles AT, Falster DS, Leishman MR, Westoby M. 2004. Small-seeded species produce more seeds per square metre of canopy per year, but not per individual per lifetime. Journal of Ecology 92: 384-396.

Moles AT, Warton DI, Warman L, Swenson NG, Laffan SW, Zanne AE, Pitman A, Hemmings FA, Leishman MR. 2009. Global patterns in plant height. Journal of Ecology 97: 923-932.

Moles AT, Westoby M. 2004. Seedling survival and seed size: a synthesis of the literature. Journal of Ecology 92: 372-383.

Muller SC, Overbeck GE, Pfadenhauer J, Pillar VD. 2007. Plant functional types of woody species related to fire disturbance in forest-grassland ecotones. Plant Ecology 189: 1-14.
Niinemets U. 1999. Components of leaf dry mass per area - thickness and density - alter leaf photosynthetic capacity in reverse directions in woody plants. New Phytologist 144: 35-47.

Niinemets U. 2001. Global-scale climatic controls of leaf dry mass per area, density, and thickness in trees and shrubs. Ecology 82: 453-469.

Ogaya R, Penuelas J. 2003. Comparative field study of Quercus ilex and Phillyrea latifolia: photosynthetic response to experimental drought conditions. Environmental and Experimental Botany 50: 137-148.

Ogaya R, Penuelas J. 2006. Contrasting foliar responses to drought in Quercus ilex and Phillyrea latifolia. Biologia Plantarum 50: 373-382.

Ogaya R, Penuelas J. 2007. Tree growth, mortality, and above-ground biomass accumulation in a holm oak forest under a five-year experimental field drought. Plant Ecology 189: 291-299.

Ogaya R, Penuelas J. 2008. Changes in leaf $\delta^{13} \mathrm{C}$ and $\delta^{15} \mathrm{~N}$ for three Mediterranean tree species in relation to soil water availability. Acta OecologicaInternational Journal of Ecology 34: 331-338.

Onipchenko VG, Makarov MI, Akhmetzhanova AA, Soudzilovskaia NA, Aibazova FU, Elkanova MK, Stogova AV, Cornelissen JHC. 2012. Alpine plant functional group responses to fertiliser addition depend on abiotic regime and community composition. Plant and Soil 357: 103-115.

Ordoñez JC, Van Bodegom PM, Witte J-PM, Bartholomeus RP, Van Hal JR, Aerts R. 2010. Plant strategies in relation to resource supply in mesic to wet environments: does theory mirror nature? American Naturalist 175: 225-239.

Pakeman RJ, Garnier E, Lavorel S, Ansquer P, Castro H, Cruz P, Dolezal J, Eriksson O, Freitas H, Golodets C et al. 2008. Impact of abundance weighting on the response of seed traits to climate and land use. Journal of Ecology 96 : 355-366.

Pakeman RJ, Leps J, Kleyer M, Lavorel S, Garnier E, Consortium V. 2009. Relative climatic, edaphic and management controls of plant functional trait signatures. Journal of Vegetation Science 20: 148-159.

Paula S, Arianoutsou M, Kazanis D, Tavsanoglu Ç, Lloret F, Buhk C, Ojeda F, Luna B, Moreno JM, Rodrigo A et al. 2009. Fire-related traits for plant species of the Mediterranean Basin. Ecology 90: 1420.

Paula S, Pausas JG. 2008. Burning seeds: germinative response to heat treatments in relation to resprouting ability. Journal of Ecology 96: 543-552.

Pillar VD, Sosinski EE. 2003. An improved method for searching plant functional types by numerical analysis. Journal of Vegetation Science 14: 323332.

Pittermann J, Sperry JS, Hacke UG, Wheeler JK, Sikkema EH. 2006. Intertracheid pitting and the hydraulic efficiency of conifer wood: the role of tracheid allometry and cavitation protection. American Journal of Botany 93: $1265-1273$.

Poorter H, Niinemets U, Poorter L, Wright IJ, Villar R. 2009. Causes and consequences of variation in leaf mass per area (LMA): a meta-analysis. New Phytologist 182: 565-588.

Poschlod P, Kleyer M, Jackel AK, Dannemann A, Tackenberg O. 2003. BIOPOP - a database of plant traits and Internet application for nature conservation. Folia Geobotanica 38: 263-271.

Pregitzer KS, DeForest JL, Burton AJ, Allen MF, Ruess RW, Hendrick RL. 2002. Fine root architecture of nine North American trees. Ecological Monographs 72: 293-309.

Preston KA, Cornwell WK, DeNoyer JL. 2006. Wood density and vessel traits as distinct correlates of ecological strategy in 51 California coast range angiosperms. New Phytologist 170: 807-818.

Pyankov VI, Kondratchuk AV, Shipley B. 1999. Leaf structure and specific leaf mass: the alpine desert plants of the Eastern Pamirs, Tadjikistan. New Phytologist 143: 131-142.

Quested HM, Cornelissen JHC, Press MC, Callaghan TV, Aerts R, Trosien F, Riemann P, Gwynn-Jones D, Kondratchuk A, Jonasson SE. 2003. Decomposition of sub-arctic plants with differing nitrogen economies: a functional role for hemiparasites. Ecology 84: 3209-3221.

Reich PB. 2014. The world-wide 'fast-slow' plant economics spectrum: a traits manifesto. Journal of Ecology 102: 275-301.

Reich PB, Ellsworth DS, Walters MB, Vose JM, Gresham C, Volin JC, Bowman WD. 1999. Generality of leaf trait relationships: a test across six biomes. Ecology 80: 1955-1969. 
Reich PB, Oleksyn J, Wright IJ. 2009. Leaf phosphorus influences the photosynthesis-nitrogen relation: a cross-biome analysis of 314 species. Oecologia 160: 207-212.

Reich PB, Tjoelker MG, Pregitzer KS, Wright IJ, Oleksyn J, Machado J-L. 2008. Scaling of respiration to nitrogen in leaves, stems and roots of higher land plants. Ecology Letters 11: 793-801.

Reich PB, Wright IJ, Cavender-Bares J, Craine JM, Oleksyn J, Westoby M, Walters MB. 2003. The evolution of plant functional variation: traits, spectra, and strategies. International Journal of Plant Sciences 164: S143-S164.

Reich PB, Wright IJ, Lusk CH. 2007. Predicting leaf physiology from simple plant and climate attributes: a global GLOPNET analysis. Ecological Applications 17: 1982-1988.

Roumet C, Urcelay C, Diaz S. 2006. Suites of root traits differ between annual and perennial species growing in the field. New Phytologist 170: 357-368.

Sardans J, Penuelas J, Ogaya R. 2008a. Drought-induced changes in C and N stoichiometry in a Quercus ilex Mediterranean forest. Forest Science 54: 513522.

Sardans J, Penuelas J, Prieto P, Estiarte M. 2008b. Changes in Ca, Fe, Mg, Mo, $\mathrm{Na}$, and $\mathrm{S}$ content in a Mediterranean shrubland under warming and drought. Journal of Geophysical Research-Biogeosciences 113: 1-11.

Schenk HJ, Jackson RB. 2002a. The global biogeography of roots. Ecological Monographs 72: 311-328.

Schenk HJ, Jackson RB. 2002b. Rooting depths, lateral root spreads and belowground/above-ground allometries of plants in water-limited ecosystems. Journal of Ecology 90: 480-494.

Shipley B. 1995. Structured interspecific determinants of specific leaf area in 34 species of herbaceous angiosperms. Functional Ecology 9: 312-319.

Shipley B, Vu TT. 2002. Dry matter content as a measure of dry matter concentration in plants and their parts. New Phytologist 153: 359-364.

Soudzilovskaia NA, Elumeeva TG, Onipchenko VG, Shidakov II, Salpagarova FS, Khubiev AB, Tekeev DK, Cornelissen JHC. 2013. Functional traits predict relationship between plant abundance dynamic and long-term climate warming. Proceedings of the National Academy of Sciences, USA 110: 18 18018184 .

Soudzilovskaia NA, Onipchenko VG, Cornelissen JHC, Aerts R. 2005. Biomass production, N: P ratio and nutrient limitation in a Caucasian alpine tundra plant community. Journal of Vegetation Science 16: 399-406.

Swaine EK. 2007. Ecological and evolutionary drivers of plant community assembly in a Bornean rain forest. $\mathrm{PhD}$ thesis, University of Aberdeen, Aberdeen, UK.

Tjoelker MG, Craine JM, Wedin D, Reich PB, Tilman D. 2005. Linking leaf and root trait syndromes among 39 grassland and savannah species. New Phytologist 167: 493-508.

Tobner CM, Paquette A, Messier C. 2013. Interspecific coordination and intraspecific plasticity of fine root traits in North American temperate tree species. Frontiers in Plant Science 4: 242.

Ustin SL, Gamon JA. 2010. Remote sensing of plant functional types. New Phytologist 186: 795-816.

Van Bodegom PM, Douma JC, Verheijen LM. 2014. A fully traits-based approach to modeling global vegetation distribution. Proceedings of the National Academy of Sciences, USA 111: 13 733-13738.

Van Bodegom PM, Douma JC, Witte JPM, Ordoñez JC, Bartholomeus RP, Aerts R. 2012. Going beyond limitations of plant functional types when predicting global ecosystem-atmosphere fluxes: exploring the merits of traitsbased approaches. Global Ecology and Biogeography 21: 625-636.

Van Bodegom PM, Sorrell BK, Oosthoek A, Bakke C, Aerts R. 2008. Separating the effects of partial submergence and soil oxygen demand on plant physiology. Ecology 89: 193-204.

Verheijen LM, Brovkin V, Aerts R, Bonisch G, Cornelissen JHC, Kattge J, Reich PB, Wright IJ, Van Bodegom PM. 2013. Impacts of trait variation through observed trait-climate relationships on performance of an Earth system model: a conceptual analysis. Biogeosciences 10: 5497-5515.

Weiher E, Van der Werf A, Thompson K, Roderick M, Garnier E, Eriksson O. 1999. Challenging Theophrastus: a common core list of plant traits for functional ecology. Journal of Vegetation Science 10: 609-620.
Westoby M. 1998. A leaf-height-seed (LHS) plant ecology strategy scheme. Plant and Soil 199: 213-227.

Westoby M, Falster DS, Moles AT, Vesk PA, Wright IJ. 2002. Plant ecological strategies: some leading dimensions of variation between species. Annual Review of Ecology and Systematics 33: 125-159.

Westoby M, Reich PB, Wright IJ. 2013. Understanding ecological variation across species: area-based vs mass-based expression of leaf traits. New Phytologist 199: 322-323.

Westoby M, Wright IJ. 2006. Land-plant ecology on the basis of functional traits. Trends in Ecology \& Evolution 21: 261-268.

White MA, Thornton PE, Running SW, Nemani RR. 2000. Parameterization and sensitivity analysis of the BIOME-BGC terrestrial ecosystem model: net primary production controls. Earth Interactions 4: 1-85.

Wirth C, Lichstein JW. 2009. The imprint of succession on old-growth forest carbon balances: insights from a trait-based model of forest dynamics. In: Wirth C, Gleixner G, Heimann M, eds. Old-growth forests: function, fate and value. Berlin, Germany: Springer, 81-113.

Wohlfahrt G, Bahn M, Haubner E, Horak I, Michaeler W, Rottmar K, Tappeiner U, Cernusca A. 1999. Inter-specific variation of the biochemical limitation to photosynthesis and related leaf traits of 30 species from mountain grassland ecosystems under different land use. Plant, Cell \& Environment 22: 1281-1296.

Woodward FI, Kelly CK. 1997. Plant functional types: towards a definition by enviromental constraints. In: Smith TM, Shugart HH, Woodward FI, eds. Plant functional types: their relevance to ecosystem properties and global change. Cambridge, UK: Cambridge University Press, 47-65.

Wright IJ, Ackerly DD, Bongers F, Harms KE, Ibarra-Manriquez G, MartinezRamos M, Mazer SJ, Muller-Landau HC, Paz H, Pitman NCA et al. 2007. Relationships among ecologically important dimensions of plant trait variation in seven Neotropical forests. Annals of Botany 99: 1003-1015.

Wright IJ, Reich PB, Atkin OK, Lusk CH, Tjoelker MG, Westoby M. 2006. Irradiance, temperature and rainfall influence leaf dark respiration in woody plants: evidence from comparisons across 20 sites. New Phytologist 169: 309319.

Wright IJ, Reich PB, Cornelissen JHC, Falster DS, Garnier E, Hikosaka K, Lamont BB, Lee W, Oleksyn J, Osada N et al. 2005. Assessing the generality of global leaf trait relationships. New Phytologist 166: 485-496.

Wright IJ, Reich PB, Westoby M, Ackerly DD, Baruch Z, Bongers F, Cavender-Bares J, Chapin T, Cornelissen JHC, Diemer M et al. 2004. The worldwide leaf economics spectrum. Nature 428: 821-827.

Wright SJ, Yavitt JB, Wurzburger N, Turner BL, Tanner EVJ, Sayer EJ, Santiago LS, Kaspari M, Hedin LO, Harms KE et al. 2011. Potassium, phosphorus, or nitrogen limit root allocation, tree growth, or litter production in a lowland tropical forest. Ecology 92: 1616-1625.

Wullschleger SD, Epstein HE, Box EO, Euskirchen ES, Goswami S, Iversen CM, Kattge J, Norby RJ, Van Bodegom PM, Xu X. 2014. Plant functional types in Earth system models: past experiences and future directions for application of dynamic vegetation models in high-latitude ecosystems. Annals of Botany 114: 1-16.

Zanne AE, Lopez-Gonzalez G, Coomes DA, Ilic J, Jansen S, Lewis SL, Miller RB, Swenson NG, Wiemann MC, Chave J. 2009. Towards a worldwide wood economics spectrum. Dryad Digital Repository. [WWW document] URL http:// dx.doi.org/10.5061/dryad.234 [accessed 16 November 2010].

Zanne AE, Westoby M, Falster DS, Ackerly DD, Loarie SR, Arnold SEJ, Coomes DA. 2010. Angiosperm wood structure: global patterns in vessel anatomy and their relation to wood density and potential conductivity. American Journal of Botany 97: 207-215.

\section{Supporting Information}

Additional supporting information may be found in the online version of this article.

Fig. S1 Data distribution per trait and PFT (seven- and six-PFT classification). 
Fig. S2 Data distribution per trait and PFT (tree PFT classification).

Fig. S3 Effect of number of species per PFT on the predictability of a PFT.

Fig. S4 Effect of axis evaluations points on model performance.

Fig. S5 Model performance in relation to number of species within each dataset.

Fig. S6 Change in model performance when an additional random trait is added.

Fig. S7 Model performance of tested trait sets for the six-PFT classification.

Fig. S8 Relative occurrence of traits in best performing trait sets for the six-PFT classification.

Fig. S9 Relative co-selection of traits with MPH and LA or LLS in the six-PFT classification.
Fig. S10 Relative co-selection of traits with LLS in the tree PFT classification.

Table S1 Occurrences of traits in different trait sets for the sevenPFT classification

Table S2 Confusion matrix for the six-PFT classification

Table S3 Confusion matrix for the tree PFT classification

Table S4 Fractions of correctly predicted PFTs for single traits in the seven-PFT classification

Table S5 Fractions of correctly predicted PFTs for single traits in the six-PFT classification

Methods S1 Determination of axis grid-size.

Please note: Wiley Blackwell are not responsible for the content or functionality of any supporting information supplied by the authors. Any queries (other than missing material) should be directed to the New Phytologist Central Office. 